\title{
Surgical pleurodesis for Vanderschueren's stage III primary spontaneous pneumothorax
}

\author{
O. Rena*, F. Massera\#, E. Papalia*, C. Della Pona\#, M. Robustellini” and C. Casadio*
}

ABSTRACT: The aim of the present study was to determine the impact of various pleurodesis procedures on post-operative morbidity and late recurrence rate after surgical treatment of Vanderschueren's stage III primary spontaneous pneumothorax.

Between January 2001 and June 2004, 208 consecutive patients (169 male and 39 female; mean (range) age 25 (12-39) yrs) were submitted to 220 video-assisted thoracoscopic surgical procedures for primary spontaneous pneumothorax. All patients underwent apical lung resection; 112 were assigned at random to mechanical pleural abrasion (group A) and 108 to apical pleurectomy (group B).

The two groups of patients showed similar characteristics. No intra- or post-operative deaths occurred. Post-operative morbidity was $6.25 \%$ for group A and $12.9 \%$ for group B; the two groups exhibited a similar persistent post-operative air leak rate (5.3\% in group $A$ and $5.5 \%$ in group $B)$, whereas haemothorax was significantly more frequent after apical pleurectomy (eight (7.4\%) cases) than after pleural abrasion (one (0.9\%) case). The mean duration of follow-up was 46 (2466) months. Late recurrence occurred in five cases (4.6\%) after apical pleurectomy, and in seven (6.2\%) after mechanical pleural abrasion.

Mechanical pleural abrasion by video-assisted thoracoscopic surgery is safer than apical pleurectomy in the treatment of primary spontaneous pneumothorax. No differences in late recurrence rate were observed between the two procedures.

\section{KEYWORDS: Pleurectomy, pleurodesis, pneumothorax, surgery, thoracoscopy}

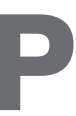
rimary spontaneous pneumothorax (PSP) is a relatively common disease but its pathophysiology remains unknown [1]. In most cases, no treatment is required other than thoracentesis or pleural drainage insertion. The recurrence rate after these treatments is considerably high; the international literature refers to a mean rate of relapse of $\sim 30 \%$ after the first episode (range 16-52\%) [2].

It is well accepted that, after the first episode, relapsing PSP requires a more invasive approach. Therapeutic options include chest drainage with instillation of pleural irritants, such as talc or tetracycline, medical thoracoscopy with talc instillation, complete pleurodesis through an open procedure and video-assisted thoracoscopic surgery (VATS) pleurodesis (mechanical pleural abrasion or apical pleurectomy; both of these procedures may or may not be associated with apical lung wedge resection). Tube thoracostomy and instillation of pleural irritants showed a relapse rate of $8-25 \%[3,4]$; medical thoracoscopy with talc poudrage is reported to be associated with a $5 \%$ failure rate after a thorough follow-up over 5 yrs [5]. Recurrence rates after VATS or open surgery range $1-14 \%$ [6-13].

Since the late 1990s, the surgical literature has widely accepted the classification of PSP by R.G. Vanderschueren [14] (table 1) as a basis of decision-making in the choice of surgical approach [12]. If operated upon, stage I and II patients without bullae are frequently treated simply by pleurodesis (pleurectomy, mechanical pleural abrasion or talc poudrage), whereas stage III and IV patients receive additional treatment of their bullae in the pathogenesis of PSP by bullae resection or electrocauterisation. Some authors question the real role of peripheral blebs or bullae in the pathogenesis of PSP [15-19]. Indeed, histopathological analysis of resected subpleural blebs or bullae has not always shown defects responsible for the air leakage [19, 20]. Hence bullectomy has not been proven necessarily to prevent recurrence, whereas pleurodesis

\section{AFFILIATIONS}

*Thoracic Surgery Unit, "A.

Avogadro" University, Novara, and "Thoracic Surgery Unit, E. Morelli Regional Hospital, Sondalo, Italy.

\section{CORRESPONDENCE}

0 . Rena

Thoracic Surgery Unit University "A. Avogadro" Via Frasconi 14 28100 Novara Italy

Fax: 393213733578

E-mail: ottaviorena@libero.it

\section{Received:}

October 302006

Accepted after revision:

November 222007

\section{SUPPORT STATEMENT}

This study was performed within the research fellowship programme "Research Doctorate in Advanced Therapies and Technologies Applied to Surgery" at Tor Vergata University (Rome, Italy).

STATEMENT OF INTEREST None declared. 


\begin{tabular}{ll} 
TABLE 1 & $\begin{array}{l}\text { Vanderschueren's classification of primary } \\
\text { spontaneous pneumothorax }\end{array}$ \\
\hline $\begin{array}{l}\text { Stage I } \\
\text { Stage II }\end{array}$ & No endoscopic abnormalities \\
Stage III & Blebs/bullae of $<2 \mathrm{~cm}$ in greatest diameter \\
Stage IV & Bullae of $>2 \mathrm{~cm}$ in greatest diameter \\
\hline
\end{tabular}

producing a diffuse pleural symphysis seems to be very effective.

Although many pneumologists have still chosen to perform pleurodesis through thoracoscopic talc instillation, VATS has been accepted as the standard procedure for the management of recurrent or persistent Vanderschueren's stage III PSP since the late 1990s. It remains controversial as to which procedure is safest and most effective in performing pleurodesis. To date, no randomised prospective study has been published comparing pleural abrasion to parietal pleurectomy, whereas postoperative morbidity and the long-term results of both procedures have been investigated and compared.

\section{MATERIAL AND METHODS}

Between January 1, 2001 and June 31, 2004, 489 patients aged $<40$ yrs affected by recurrent or persistent PSP (air leak from the pleural drainage at first episode persisting for $>5$ days) were referred to the thoracic surgery units of "A. Avogadro" University (Novara, Italy) and E. Morelli Regional Hospital (Sondalo, Italy) for surgical management. All patients were submitted to three-portal VATS. General anaesthesia was administered with double-lumen intubation. The patient was placed on the operating table as for muscle-sparing lateral thoracotomy. Single-lung ventilation was begun before a 1.5$\mathrm{cm}$ skin incision was made in the sixth intercostal space in the midaxillary line, and a $0^{\circ} 10-\mathrm{mm}$ video-thoracoscope (Karl Storz, Tuttlingen, Germany) was introduced through a 10.5$\mathrm{mm}$ thoracoport. Two further trocars were introduced, under endoscopic guidance, through the fourth intercostal space in the anterior axillary line and through the fifth intercostal space in the auscultatory triangle, respectively. The lung was inspected during gentle ventilation with saline solution in the pleural cavity to detect air leak or small blebs and bullae. Pathological lesions diagnosed during endoscopic examination were classified according to Vanderschueren's classification [14], as follows. Stage I: no endoscopic abnormalities $(n=47$; $9.6 \%)$; stage II: pleuropulmonary adhesions ( $\mathrm{n}=99 ; 20.2 \%)$; stage III: blebs/bullae of $<2 \mathrm{~cm}(n=208 ; 42.5 \%)$; and stage IV: bullae of $>2 \mathrm{~cm}(\mathrm{n}=135 ; 27.6 \%)$.

The present article focuses on 208 patients affected by stage III Vanderschueren's PSP. All patients were submitted to minimal wedge resection of their blebs or bullae with an endoscopic stapler (SCB 45; Ethicon Endosurgery, Inc., Cincinnati, OH, USA). Surgical pleurodesis was carried out by endoscopic mechanical abrasion or parietal pleurectomy. Patients were assigned at random to undergo one of the two procedures after the initial endoscopic evaluation. Group A patients were submitted to mechanical pleural abrasion using a Marlex ${ }^{\mathrm{TM}}$ mesh (Bard ${ }_{\circledR}$ Mesh; C.R. Bard, Inc., Murray Hill, NJ, USA) attached to the tip of a standard endoscopic grasper; abrasion was stopped when a uniform aspect of bloody pleura was obtained. Group B patients were submitted to endoscopic parietal pleurectomy. The portion of pleural surface submitted to surgical pleurodesis was the same for the two groups, in order to permit successive comparison. Parietal pleurectomy or mechanical abrasion were carried out from the fifth rib, either on the left side up to the level of the subclavian artery or on the right side up to the brachiocephalic trunk; the front and rear limits were $1 \mathrm{~cm}$ laterally from the sympathetic nerve chain and $1 \mathrm{~cm}$ laterally from the internal mammalian artery, respectively. Mediastinal pleura was not involved by the surgical procedure. Surgeons of both institutions were familiar with both techniques, which were carried out in the same way in both centres (any one of the present authors participated in all of the procedures); 114 patients were randomised at the "A. Avogadro" University (group A: $n=58$; group B: $n=56$ ) and 106 at the E. Morelli Regional Hospital (group A: $n=54$; group B: $n=52$ ).

A $28 \mathrm{~F}$ chest tube was placed through the inferior incision and adequate lung re-expansion was monitored. The tube was connected to underwater seal suction with a negative pressure of $10 \mathrm{cmH}_{2} \mathrm{O}$ during the first $6 \mathrm{~h}$ after surgery, to permit easy and immediate detection of pleural haemorrhage. Surgical specimens were systematically sent to the pathology department of the relevant hospital for pathological examination and to confirm bleb and bullae dimensions, and were subsequently revised by one pathologist from the "A. Avogadro" University.

Patients were extubated in the operating theatre and carried to the ward after $4-6 \mathrm{~h}$ of observation in the intermediate care unit. Daily chest radiography was carried out on each patient. The chest tube was usually removed when air leak had resolved, the lung had fully expanded and pleural drainage was $<100 \mathrm{~mL} \cdot 24 \mathrm{~h}^{-1}$. Nonsteroidal anti-inflammatory drugs were not administered during the entire post-operative period in order to avoid post-operative bleeding and interference during the process of pleural adhesion formation. Daily postoperative pain was measured using a visual analogue scale (graded 0-10) and recorded. Post-operative analgesia was secured with continuous intravenous $0.15 \mathrm{mg} \cdot \mathrm{kg}$ body weight $^{-1} \cdot \mathrm{h}^{-1}$ tramadol plus $1.2 \mathrm{mg} \cdot \mathrm{kg}$ body weight ${ }^{-1} \cdot \mathrm{h}^{-1}$ paracetamol until the chest tube was removed. Patients were discharged the day after chest tube removal. After discharge, each patient was followed-up for a mean (range) period of 46 (24-66) months; chest radiography and clinical observation were carried out at 1, 3, 6, 12, 18 and 24 months, and annually after the first 24 months, until June 2006. During the periodical visits of the first 6 months, patients were asked about their residual wound pain and paraesthesia (a disordered sensation causing chest wall discomfort that can be easily distinguished from wound pain) and were requested to express it using the same visual analogue scale as they had used while in hospital. Pneumothorax recurrence was defined as a pneumothorax of $>10 \%$ of the size of the hemithorax, diagnosed through chest radiography and confirmed by chest computed tomography.

Evaluation of the results of both techniques was carried out, measuring the following factors: operative time, early and long-term post-operative pain and chest discomfort, amount of pleural drainage (post-operative blood loss), duration of chest drainage, post-operative complications, post-operative duration of hospital stay, and incidence of late recurrence. 
All data are presented as mean \pm SD. An unpaired t-test was used for the statistical analysis. Pearson's Chi-squared test was used to ascertain significance between categorical variables. A p-value of $<0.05$ was taken as significant.

The present study was authorised by the internal ethics committee of both institutions, and all patients expressed and signed their pre-operative consent.

\section{RESULTS}

During the period of the study, 220 consecutive procedures were carried out on 208 patients for either first recurrent or persistent spontaneous pneumothorax in Vanderschueren's stage III patients. The patients' characteristics are illustrated in table 2. There were no differences in age, sex, weight, height or smoking status, and clinical appearance was similar.

Of the 208 patients, 12 were submitted to VATS for contralateral PSP during the follow-up period. Mechanical abrasion was carried out in 112 procedures (group A), whereas apical parietal pleurectomy was performed in 108 (group B). The mean operating time was higher for group B than for group A ( $55 \pm 18$ versus $38 \pm 16 \mathrm{~min}$, respectively), a significant difference $(p=0.0001)$. Post-operative acute bleeding $\left(>200 \mathrm{~mL} \cdot \mathrm{h}^{-1}\right.$ for $3 \mathrm{~h}$ consecutively after the operation) was observed in eight out of $108(7.4 \%)$ procedures in group B and in one out of $112(0.9 \%)$ procedures in group $\mathrm{A}$; this difference was significant $(p=0.036)$. The above-mentioned nine patients were submitted to immediate re-intervention, with removal of the blood clot and haemostasis; the remainder of the post-operative period was uneventful.

The mean chest drain duration was $2.53 \pm 1.55$ days for group A patients and $2.92 \pm 1.71$ days for group B patients; no significant differences were detected $(p=0.065)$. The persistent air leak rate was similar for the two groups; in six out of 112 $(5.3 \%)$ procedures in group A and in six out of $108(5.5 \%)$ procedures in group $B$, air leakage lasted $>5$ days $(p=0.978)$. The mean post-operative chest drain duration for these cases was $8.17 \pm 1.72$ days in group A and $8.67 \pm 2.34$ days in group B. Thanks to minimal air loss, most patients were observed until the complication resolved spontaneously. One patient from each group had large air leak on post-operative day 5 and was resubmitted to VATS; in both cases, an imperfect stapler

\begin{tabular}{lccc} 
TABLE 2 & Pneumothorax patient characteristics & \\
& Group A & Group B & p-value \\
\hline & & & \\
Age yrs & $24.5 \pm 6.89$ & $25 \pm 6.51$ & 0.580 \\
Male sex & $84 / 106(79.3)$ & $85 / 102(83.3)$ & 0.575 \\
Right side & $62 / 112(55.3)$ & $63 / 108(58.3)$ & 0.753 \\
Smoker & $46 / 106(43.3)$ & $52 / 102(49.5)$ & 0.458 \\
Weight kg & $65 \pm 10.8$ & $63 \pm 9.5$ & 0.145 \\
Height cm & $174 \pm 9.7$ & $176 \pm 8.2$ & 0.121 \\
Clinical appearance $\mathbf{n}$ (\%) & & & \\
$\quad$ Recurrent & $91(81.25)$ & $86(80)$ & 0.986 \\
$\quad$ Persistent & $21(18.75)$ & $22(20)$ & 0.949 \\
\hline
\end{tabular}

Data are presented as mean \pm SD or $\mathrm{n} / \mathrm{N}(\%)$, unless otherwise indicated. $\mathrm{N}$ represents the total number of procedures performed. line suture was detected and the endoscopic stapler was re-applied with complete control of the air leakage. Chest tubes were removed on days 2 and 3 after the second operation.

Post-operative pain levels are illustrated in table 3. Early postoperative pain was not dependent upon the pleurodesis technique adopted. Considering the overall post-operative period, group B patients demonstrated significantly greater residual chest pain and discomfort than group A patients $(\mathrm{p}=0.001)$.

The mean duration of hospital stay depended upon chest drain duration, and was $3.52 \pm 1.55$ days in group $\mathrm{A}$ and $3.89 \pm 1.71$ days in group $B$; no difference was recorded $(p=0.08)$.

After the first 24 months of the follow-up period, $25(18.8 \%)$ patients from group A and $18(16.7 \%)$ from group B could not be tracked down. Recurrence occurred in five (4.6\%) cases after parietal pleurectomy and seven $(6.2 \%)$ after mechanical pleural abrasion $(\mathrm{p}=0.821)$. The mean (range) recurrence time was $11.57 \pm 12.57$ (1-32) months in group A and 11.4 \pm 15.34 (138 ) months in group $B$, a nonsignificant difference $(p=0.984)$. One out of five $(20 \%)$ recurrences in group B and two out of seven $(28.5 \%)$ in group A occurred $>24$ months after the surgical treatment. Two out of seven recurrences in group A were limited and treated by observation alone; the other five required resubmission to VATS and pleural abrasion. One out of five recurrences in group B was treated by observation alone due to it being limited, whereas the other four required resubmission to VATS and pleural abrasion. As far as the requirement for repeat surgery for the treatment of the late recurrences is concerned, there was no difference between the two groups.

\section{DISCUSSION}

So-called PSP primarily affects young healthy people and remains a global problem, with an annual incidence of 18-28 per 100,000 population in males and $1.2-6.0$ per 100,000 population in females [21]. Smoking is a relevant risk factor for PSP; recently the British Thoracic Society (BTS) Pleural Disease Group emphasised the relationship between smoking and the recurrence of pneumothorax [22]. The pathophysiology

\begin{tabular}{lccc} 
TABLE 3 & $\begin{array}{c}\text { Early and long-term post-operative (PO) pain } \\
\text { and analgesic drug requirement }\end{array}$ & p-value \\
PO day & \multicolumn{2}{c}{ VAS grading } & \\
\cline { 2 - 3 } & Group A & Group B & \\
\hline & & & NS \\
$\mathbf{0}$ & $3.04 \pm 0.96$ & $3.23 \pm 0.94$ & NS \\
$\mathbf{1}$ & $2.41 \pm 0.99$ & $2.48 \pm 0.99$ & NS \\
$\mathbf{2}$ & $1.95 \pm 0.93$ & $1.98 \pm 0.87$ & NS \\
$\mathbf{3}$ & $1.68 \pm 0.84$ & $1.71 \pm 0.75$ & NS \\
$\mathbf{7}$ & $1.38 \pm 0.96$ & $1.41 \pm 0.84$ & 0.04 \\
$\mathbf{3 0}$ & $0.68 \pm 0.80$ & $0.91 \pm 0.96$ & 0.04 \\
$\mathbf{9 0}$ & $0.48 \pm 0.38$ & $0.61 \pm 0.63$ & 0.001 \\
$\mathbf{1 8 0}$ & $0.31 \pm 0.64$ & $0.58 \pm 0.61$ & \\
\hline
\end{tabular}

Data are presented as mean \pm SD. VAS: visual analogue scale $(0-10)$; NS: nonsignificant. 
of pneumothorax remains unclear. Although rupture of blebs and bullae has been considered to be the main cause of spontaneous pneumothorax, there is a paucity of evidence for this theory in the literature and it is now considered controversial [2].

In the past, some authors have indicated that histopathological analysis of surgically resected subpleural blebs or bullae has not always revealed holes responsible for air leakage on the resected material [19, 20]. Comparing video thoracoscopic findings in patients with a first episode to those in patients with recurrent pneumothorax, JANSEN et al. [15] did not find any more blebs or bullae in recurrent PSP. This would suggest that blebs or bullae are not a major risk factor for PSP. Three recent nonrandomised reports on the results of treatment of PSP by bullectomy alone have suggested that bullectomy without pleurodesis does not prevent recurrence of PSP [15, 19, 20]. Improvements in imaging using computed tomography showed diffuse and bilateral blebs in patients treated for unilateral PSP; these changes (the so-called emphysema-like changes that seem to be related to smoking) might be grounds for lung tissue destruction, and might contribute to the occurrence of PSP and relevant recurrences. However, there is no evidence that these parenchymal changes are the unique cause of pneumothorax. Distal airway inflammation due to cigarette smoking probably play a fundamental role [23]. According to these reports, bullectomy alone does not appear to be enough to prevent recurrence, whereas pleurodesis, by producing a diffuse pleural symphysis, might be effective against any of the causes of pneumothorax that have not yet been clearly demonstrated.

Physicians and surgeons worldwide broadly agree that, at its first occurrence, PSP should be managed conservatively (ranging from observation to chest drain insertion), given that only $20-25 \%$ of patients experiences a recurrence [2, 22-24]. PSPs should be surgically treated only in the case of persistent air leakage after chest drainage during the first episode, or in the case of ipsilateral or contralateral recurrence [2, 22-24]. Although blebs or bullae are not always proved to be the real causes of first-episode PSP and its recurrences, nowadays, when apical blebs or bullae are identified in the surgical world, blebectomy or bullectomy is considered to be a rational part of the treatment of complicated PSP [25]. Minimally invasive surgical approaches to blebectomy or bullectomy are desirable. In 1998, MASSARD et al. [25] published a review about minimally invasive management of first and recurrent pneumothorax, and analysed the immediate and long-term results of axillary minithoracotomy and video-assisted surgery. They concluded that video-assisted thoracoscopy is not superior to axillary minithoracotomy when post-operative duration of hospital stay, the related morbidity and long-term outcome are compared.

The role of pleurodesis has been clearly established [26] but the choice of method for the prevention of pneumothorax recurrence remains controversial. Methods of promoting adequate pleural symphysis include instillation of talc, mechanical abrasion, apical pleurectomy and extended pleurectomy $[8,10,12,27]$. Although, in an experimental study, talc insufflation produced the most widespread firm fibrotic adhesions, the American College of Chest Physicians and
BTS do not consider talc pleurodesis an appropriate initial treatment for complicated PSP [23, 24, 28]. Mechanical pleural abrasion and apical pleurectomy are considered acceptable VATS pleurodesis techniques [23, 24]. Some authors avoid pleurectomy and prefer mechanical abrasion, not only due to the increased morbidity associated with the former but also the possibility that it could impair later operations. CHAN et al. [29] reported a high risk of bleeding and post-operative neuralgia in apical pleurectomy. However, in the retrospective study of AYED and AL-DIN [12], apical pleurectomy was found to be more effective at producing pleural symphysis than pleural abrasion. To date, there are no randomised trials comparing different pleurodesis techniques.

In the present study, mechanical pleural abrasion and apical pleurectomy were randomly assigned to patients affected by Vanderschueren's stage III PSP submitted to endoscopic stapling of the lung.

The operative results showed that mechanical pleural abrasion is significantly safer (lesser rate of post-operative bleeding requiring re-intervention) and involves a shorter operating time than apical pleurectomy. Conversely, prolonged postoperative air leak appeared to be similar for both surgical procedures, indicating that continued air leak should not be attributed to surgical pleurodesis failure. In only one case from each group was the cause of the persistent air leakage detected, with, on submission to repeat VATS, the leakage being found to be due to a faulty stapler line. In the other cases, the postoperative air leaks decreased and resolved spontaneously and their causes were never detected. Crossing of staplers, traction tearing of the lung and missed blebs or bullar lesions have been recognised to be important reasons for a prolonged postoperative course $[7,12,29]$.

Mechanical pleural abrasion and apical pleurectomy appeared to be equivalent as far as immediate post-operative chest pain was concerned. The relatively high proportion of patients with moderate post-operative pain was probably due to the present decision not to use anti-inflammatory drugs as analgesics, both to reduce the risk of post-operative bleeding and so as not to influence the process of pleural adhesion after abrasion or pleurectomy. Patients submitted to apical pleurectomy experienced mild chest pain and discomfort of longer duration than in those submitted to apical pleural abrasion, as previously described in the literature [29]. This is probably related to intercostal nerve damage, which is more extensive during pleurectomy than during pleural abrasion.

Duration of hospital stay is directly related to the occurrence of post-operative complications, particularly persistent air leak. The same incidence of this post-operative morbid condition among patients submitted to either pleurectomy or pleural abrasion led to a nonsignificant difference in the duration of the stay in hospital for the two procedures.

Even though some reports have suggested that apical pleurectomy is more efficient than pleural abrasion in preventing recurrent pneumothorax, the present study did not demonstrate any difference in recurrence rate when the two procedures were compared [12, 29]. The overall recurrence rate at a mean follow-up time of 46 months was 5.4\%, ranging from $4.6 \%$ for apical pleurectomy to $6.2 \%$ for pleural abrasion. 
This recurrence rate was comparable to those reported in the literature, ranging $3-5.7 \%[6-13,29]$.

In summary, its shorter operating time and lower procedurerelated morbidity (immediate post-operative bleeding and postoperative chest pain duration) proved that pleural abrasion is safer than apical pleurectomy for the treatment of complicated primary spontaneous pneumothorax, whereas their long-term efficacy in preventing recurrent pneumothorax seems to be the same. Therefore, the present authors recommend pleural abrasion as pleurodesis procedure in young healthy people when video-assisted thoracoscopic surgical blebectomy or bullectomy is considered necessary for Vanderschueren's stage III primary spontaneous pneumothorax.

\section{REFERENCES}

1 Tschopp JM, Rami-Porta R, Noppen M, Astoul P. Management of spontaneous pneumothorax: state of the art. Eur Respir J 2006; 28: 637-650.

2 Schramel FM, Postmus PE, Vanderschueren RG. Current aspects of spontaneous pneumothorax. Eur Respir J 1997; 10: $1372-1379$.

3 Light RW, O'Hara VS, Moritz TE. Intrapleural tetracycline for the prevention of recurrent spontaneous pneumothorax: results of a Department of Veterans Affairs cooperative study. JAMA 1990; 264: 2224-2230.

4 Almind M, Lange $\mathrm{P}$, Viskum K. Spontaneous pneumothorax: comparison of simple drainage, talc pleurodesis, and tetracycline pleurodesis. Thorax 1989; 44: 627-630.

5 Tschopp JM, Boutin C, Astoul P, et al. Talcage by medical thoracoscopy for primary spontaneous pneumothorax is more cost-effective than drainage: a randomised study. Eur Respir J 2002; 20: 1003-1009.

6 Sahn SA, Heffner JE. Spontaneous pneumothorax. N Engl J Med 2000; 342: 868-874.

7 Bertrand PC, Regnard JF, Spaggiari L. Immediate and long-term results after surgical treatment of primary spontaneous pneumothorax by VATS. Ann Thorac Surg 1996; 61: 1641-1645.

8 Moroux J, Elkaim D, Padovani B, et al. Video-assisted thoracoscopic treatment of spontaneous pneumothorax: technique and results of one hundred cases. J Thorac Cardiovasc Surg 1996; 112: 385-391.

9 Korner H, Anderson KS, Stangeland L, Ellingsen I, Engedal H. Surgical treatment of spontaneous pneumothorax by wedge resection without pleurodesis or pleurectomy. Eur J Cardiothorac Surg 1996; 10: 656-659.

10 Leo F, Pastorino U, Goldstraw P. Pleurectomy in primary pneumothorax: is extensive pleurectomy necessary? J Cardiovasc Surg 2000; 41: 633-636.

11 Lang-Lazdunski L, Chapuis O, Bonnet PM, Pons F, Jancovici R. Videothoracoscopic bleb excision and pleural abrasion for the treatment of primary spontaneous pneumothorax: long-term results. Ann Thorac Surg 2003; 75: 960-965.

12 Ayed AK, Al-Din HJ. The results of thoracoscopic surgery for primary spontaneous pneumothorax. Chest 2000; 118: 235-238.

13 Casadio C, Rena O, Giobbe R, Rigoni R, Maggi G, Oliaro A. Stapler blebectomy and pleural abrasion by video-assisted thoracoscopy for spontaneous pneumothorax. J Cardiovasc Surg 2002; 43: 259-262.

14 Vanderschueren RG. Le talcage pleural dans le pneumothorax spontane. [Pleural talcage in patients with spontaneous pneumothorax.] Poumon Coeur 1981; 37: 273-276.

15 Janssen JP, Scharmel FMNH, Sutedja TG, Cuesta MA, Oosterhuis WP, Postmus PE. Videothoracoscopic appearance of first and recurrent pneumothorax. Chest 1995; 108: 330-334.

16 Hatz RA, Kaps MF, Meimarakis G, Loehe F, Muller C, Furst $\mathrm{H}$. Long-term results after surgery for first-time and recurrent spontaneous pneumothorax. Ann Thorac Surg 2000; 70: 253-257.

17 Horio H, Nomori H, Kobayaski R, Narube T, Suemasu K. Impact of additional pleurodesis in video-assisted thoracoscopic bullectomy for primary spontaneous pneumothorax. Surg Endosc 2002; 16: 630-634.

18 Loubani M, Lynch V. Video-assisted thoracoscopic bullectomy and acromycin pleurodesis: an effective treatment for spontaneous pneumothorax. Respiration 1992; 59: 221-227.

19 Radomsky J, Becker HP, Hartel W. Pleuroporositat beim idiopatischen Spontanpneumothorax. [Pleural porosity in idiopathic spontaneous pneumothorax.] Pneumologie 1989; 43: 394-408.

20 Ohata M, Suzuki H. Pathogenesis of spontaneous pneumothorax. With special reference to the ultrastructure of emphysematous bullae. Chest 1980; 77: 771-776.

21 Gupta D, Hansell A, Nichols T, Duong T, Ayres JG, Strachan D. Epidemiology of pneumothorax in England. Thorax 2000; 55: 666-671.

22 Henry M, Arnold T, Harvey J, Pleural Disease Group, Standards of Care Committee, British Thoracic Society. BTS guidelines for the management of spontaneous pneumothorax. Thorax 2003; 58: Suppl. 2, ii39-ii52.

23 Smit HJM, Devillè WL, Schramel FM, Postmus PE. Spontaneous pneumothorax: predictable mini-epidemics? Lancet 1997; 350: 1450.

24 Baumann MH, Strange C, Heffner JE, et al. Management of spontaneous pneumothorax. An American College of Chest Physicians Delphi consensus statement. Chest 2001; 119: 590-602.

25 Massard G, Thomas P, Wihlm JM. Minimally invasive management for first and recurrent pneumothorax. Ann Thorac Surg 1998; 66: 592-599.

26 Inderbitzy RG, Leiser A, Furrer M, Althaus U. Three years' experience in video-assisted thoracic surgery (VATS) for spontaneous pneumothorax. J Thorac Cardiovasc Surg 1994; 107: 1410-1415.

27 Cardillo G, Carleo F, Giunti R, et al. Videothoracoscopic talc poudrage in primary spontaneous pneumothorax: a single-institution experience in 861 cases. I Thorac Cardiovasc Surg 2006; 131: 322-327.

28 Colt HG, Russack V, Chiu Y, et al. A comparison of thoracoscopic talc insufflation, slurry, and mechanical abrasion pleurodesis. Chest 1997; 111: 442-448.

29 Chan P, Clarke P, Daniel FJ, Knight SR, Seevanayagam S. Efficacy study of video-assisted thoracoscopic surgery pleurodesis for spontaneous pneumothorax. Ann Thorac Surg 2001; 71: 452-454. 